\title{
Electrodeposition of Vanadium Oxide/Manganese Oxide Hybrid Thin Films on Nanostructured Aluminum Substrates
}

\author{
David Rehnlund, ${ }^{\mathrm{Z}}$ Mario Valvo, ${ }^{*}$ Kristina Edström, ${ }^{* *}$ and Leif Nyholm ${ }^{* *}$ \\ Department of Chemistry, Ångström Laboratory, Uppsala University, Uppsala, Sweden
}

\begin{abstract}
Electrodeposition of functional coatings on aluminum electrodes in aqueous solutions often is impeded by the corrosion of aluminum. In the present work it is demonstrated that electrodeposition of vanadium oxide films on nanostructured aluminum substrates can be achieved in acidic electrolytes employing a novel strategy in which a thin interspacing layer of manganese oxide is first electrodeposited on aluminum microrod substrates. Such deposited films, which were studied using SEM, XPS, XRD, and surface enhances Raman scattering as well as chronopotentiometry, are shown to comprise a mixture of vanadium oxidation states (i.e. IV and V). As this all-electrochemical approach circumvents the problems associated with aluminum corrosion, the approach provides new possibilities for the electrochemical coating of nanostructured $\mathrm{Al}$ substrates with functional layers of metal oxides. The latter significantly facilitates the development of new procedures for the manufacturing of three-dimensional aluminum based electrodes for lithium ion microbatteries.

(c) The Author(s) 2014. Published by ECS. This is an open access article distributed under the terms of the Creative Commons Attribution 4.0 License (CC BY, http://creativecommons.org/licenses/by/4.0/), which permits unrestricted reuse of the work in any medium, provided the original work is properly cited. [DOI: 10.1149/2.0511410jes] All rights reserved.
\end{abstract}

Manuscript submitted April 17, 2014; revised manuscript received June 17, 2014. Published July 16, 2014. This was Paper 2282 presented at the San Francisco, California, Meeting of the Society, October 27-November 1, 2013.

The continuous miniaturization within the field of electronics has created increased interest in the modification of nanostructured substrates and electrodeposition has emerged as a particularly promising technique for straightforward and cost-effective preparation of threedimensional (3D) structures, allowing the realization of nanostructures with functional layers. ${ }^{1,2}$ The fact that the fabrication and coating of complex 3D nanostructures can be carried out at low temperatures with precise control differentiates electrochemical deposition from other thin film deposition techniques including physical vapor deposition (PVD), chemical vapor deposition (CVD) and atomic layer deposition (ALD). ${ }^{1}$ Template-assisted electrodeposition has been demonstrated to be a particularly versatile technique in the manufacture of nanostructured substrates, such as 3D arrays of copper ${ }^{3,4}$ and aluminum nanorods. ${ }^{5,6}$ Whereas the deposition of copper nanostructures is relatively straightforward, the corresponding deposition of aluminum nanostructures is more demanding ${ }^{1}$ due to the need for non-aqueous solutions and a controlled oxygen-free atmosphere. Electrochemical deposition of layers of functional material on aluminum from aqueous solutions is further complicated by the fact that the aluminum surface is coated by a passivating $\mathrm{Al}_{2} \mathrm{O}_{3}$ film between $\mathrm{pH} 5$ and 8 , while there is aluminum corrosion in acidic as well as alkaline solutions. ${ }^{7}$

Aluminum has a wide field of application mainly due to its low cost, low weight and high thermal and electronic conductivities. ${ }^{8}$ Much work has therefore been carried out to develop techniques for the protection of $\mathrm{Al}$ surfaces from corrosion, e.g. based on electrodeposition of protecting polymer layers on planar aluminum substrates. ${ }^{8-10}$ In addition, a significant interest in investigating the possibilities for electrodeposition of electroactive layers on aluminum nanostructures has recently arisen as a result of the success in the manufacturing of electrodeposited 3D aluminum substrates for Li-ion microbatteries. ${ }^{5,6}$ Since these 3D electrode structures offer the possibility to incorporate a larger amount of electroactive material on the same footprint area, this approach is particularly interesting for microelectromechanical systems (MEMS) in which highly efficient components need to be fitted into a very limited space. ${ }^{11} 3 \mathrm{D}$ aluminum substrates coated with thin functional films can hence give rise to both a compatibility with high charge and discharge rates as well as increased charge storage capacities per footprint area. ${ }^{12} \mathrm{Up}$ to now functionalisation of $3 \mathrm{D}$ aluminum substrates has been limited to $\mathrm{TiO}_{2}$ thin film coating employing atomic layer deposition (ALD). ${ }^{13}$ Although the resulting 3D electrodes exhibited promising performance both for energy conversion ${ }^{14}$ and energy storage,${ }^{15}$ the ALD approach is, however, less

*Electrochemical Society Student Member

**Electrochemical Society Active Member.

${ }^{\mathrm{z} E}$ E-mail: david.rehnlund@kemi.uu.se attractive in terms of cost and versatility when compared to electrodeposition. Electrodeposition of functional coatings on nanostructured aluminum substrates could hence provide new possibilities for the realization of new electrochemical devices. As the electrodeposition processes often need to be carried out in acidic or alkaline solution, this, however, requires that the issues related to aluminum corrosion (which can be expected to be more pronounced for large surface area 3D architectures than for planar substrates) are solved. There is consequently a need for a development of new electrochemical approaches facilitating the deposition of functional layers on aluminum surfaces.

It is well-known ${ }^{16,17}$ that vanadium oxide films can serve as excellent functional coatings for various applications due to their wide optical bandgap $(2.5 \mathrm{eV}),{ }^{16}$ layered structure, good chemical and thermal stability, interesting electrochemical behavior and excellent thermoelectric and electrochromic properties. These features make vanadium oxides attractive for use in many applications, including e.g. gas sensors, electrochromic devices, optical switches, ${ }^{17}$ and Liion batteries. ${ }^{16,18}$ In a $3 \mathrm{D}$ Li-ion microbattery, a thin layer vanadium oxide could be used as a cathode material if such a layer could be successfully electrodeposited on a nanostructured Al substrate. Although other techniques including ALD, ${ }^{19}$ sputtering, ${ }^{20}$ chemical vapor deposition ${ }^{21}$ and sol-gel techniques ${ }^{22}$ have been employed to deposit vanadium oxide films, these methods are generally associated with complicated approaches and high processing costs when applied to the preparation of nanostructured electrodes. In this scenario, electrodeposition stands out as a simple and elegant method to synthesize vanadium oxides with precise control of the microstructure, surface morphology and homogeneity of the deposited oxide films. ${ }^{23}$ Electrochemical oxidation from $\mathrm{VOSO}_{4}$ solutions to yield hydrated, poorly crystalline $\mathrm{V}_{2} \mathrm{O}_{5}$ has thus been demonstrated as an effective technique in the making of electroactive vanadium oxide coatings. ${ }^{24}$ Although vanadium oxide has been electrodeposited on substrates such as platinum-coated quartz, ${ }^{24}$ graphite rods, ${ }^{25}$ indium tin oxide $(\mathrm{ITO})^{26}$ and polycarbonate membranes sputtered with $\mathrm{Au}-\mathrm{Pd},{ }^{27}$ we are not aware of any successful depositions on aluminum electrodes. Since this most likely is due to the aluminum corrosion taking place in the acidic solutions generally employed in the depositions, ${ }^{21-24}$ it is clear that the development of an all-electrochemical process for the manufacturing of vanadium oxide coated 3D aluminum substrates represents a significant challenge. This means that electrodeposition of vanadium oxide on aluminum microrods can serve as an excellent model system for the development of new approaches for electrochemical modification of aluminum substrates.

In the present work, a novel all-electrochemical synthesis route to manufacture nanostructured aluminum substrates coated with a functional material is presented. It is demonstrated for the first 
time that the presence of an initial thin electrodeposited layer of manganese oxide enables subsequent deposition of a functional layer of vanadium oxide from acidic aqueous solutions. Although this study focuses on vanadium oxide thin film coatings, the present strategy should be generally applicable for electrochemical oxidative depositions on aluminum substrates, which subsequently may be used e.g. as nanostructured electrodes in 3D lithium ion batteries. This versatile approach to circumvent the aluminum corrosion problem as well as the characteristics of the obtained materials are discussed based on results obtained with SEM, XPS, XRD, surface enhanced Raman scattering and chronopotentiometry.

\section{Experimental}

Al microrod electrodeposition. - The electrodeposition of the aluminum microrods and all other electrochemical experiments were carried out with an Autolab PGSTAT30 potentiostat/galvanostat. 3D structures made of freestanding $\mathrm{Al}$ microrods were electrodeposited as previously described by Oltean et al. ${ }^{5}$ In brief, the Al microrods were fabricated using pulsed electrodeposition using a cathodic galvanostatic pulse of $5 \mathrm{~mA} / \mathrm{cm}^{2}$ for $0.2 \mathrm{~s}$ followed by a resting pulse of $0 \mathrm{~mA} / \mathrm{cm}^{2}$ for $2 \mathrm{~s}$ employing a polycarbonate membrane (Cyclopore, Whatman) template with $1 \mu \mathrm{m}$ wide pores and an ionic liquid electrolyte (1-ethyl-3-methylimidazolium chloride/aluminum chloride 1:2 molar ratio). An analogous polycarbonate membrane with a pore size of $200 \mathrm{~nm}$ was also used for the sol-gel deposition experiments. To yield $\mathrm{Al}$ microrods with an approximate length of $8 \mu \mathrm{m}$, the pulsed deposition scheme was repeated for 6000 cycles. As the resting pulse ensured that the $\mathrm{Al}^{3+}$ concentration in the pores always was maintained sufficiently high to avoid reductive degradation of the electrolyte, the use of this pulsed technique was crucial to obtain well-defined Al microrods. Free-standing Al microrods were subsequently obtained by dissolving the polycarbonate membrane in dichloromethane (SigmaAldrich) at room temperature during 15 minutes. After the deposition, the nanostructured aluminum substrates were rinsed with ethanol prior to subsequent coating with $\mathrm{MnO}_{\mathrm{x}}$ and vanadium oxide. In the latter depositions, nanostructured electrodes with a footprint area of $1 \mathrm{~cm}^{2}$ were immersed in the electrolyte leaving an exposed electroactive area of about $0.5 \mathrm{~cm}^{2}$. The deposition of vanadium oxide on the aluminum microrods was performed in two steps involving an initial cathodic galvanostatic electrodeposition of $\mathrm{MnO}_{\mathrm{x}}$ followed by a potentiostatic oxidation of $\mathrm{VO}^{2+}$ to yield vanadium oxide as is described further below.

$\mathrm{MnO}_{x}$ electrodeposition.- The cathodic electrodeposition of $\mathrm{MnO}_{\mathrm{x}}$ on the $1 \mu \mathrm{m}$ diameter $\mathrm{Al}$ rods was carried out using an 5 $\mathrm{mM} \mathrm{MnCl} \mathrm{M}_{2}$ electrolyte obtained by dissolving $\mathrm{MnCl}_{2} \cdot 4 \mathrm{H}_{2} \mathrm{O}$ and $0.4 \mathrm{~g} / \mathrm{L}$ polyethylenimine (PEI) (Sigma Aldrich) in a mixture of 5 vol.\% water and 95 vol\% ethanol. The experiments were made using a three-electrode set-up with the 3D Al substrate as the working electrode where an $\mathrm{Ag} / \mathrm{AgCl}$ ( $\mathrm{KCl}$ sat'd) electrode and a $\mathrm{Pt}$ wire served as the reference and counter electrodes, respectively. In this case, a pulsed deposition scheme was adopted including a cathodic deposition pulse of $2 \mathrm{~mA} / \mathrm{cm}^{2}$ for $0.1 \mathrm{~s}$ and a resting pulse of $0 \mathrm{~A} / \mathrm{cm}^{2}$ for $2 \mathrm{~s}$. The thickness of the resulting $\mathrm{MnO}_{\mathrm{x}}$ films was adjusted by varying the number of program cycles between 100 and 400 following previous work on $\mathrm{MnO}_{\mathrm{x}}$ electrodeposition. ${ }^{28}$

Vanadium oxide electrodeposition. - The electrodeposition of $\mathrm{V}_{2} \mathrm{O}_{5}$ was carried out based on the work by Potiron et al. ${ }^{24}$ and Takahashi et al. ${ }^{27}$ using a $0.1 \mathrm{M}$ vanadyl sulfate solution prepared by adding $\mathrm{VOSO}_{4}$ (Sigma Aldrich) to de-ionized water under continuous stirring, followed by $\mathrm{pH}$ adjustment to 2.70 by addition of $1 \mathrm{M} \mathrm{H}_{2} \mathrm{SO}_{4}$ and $1 \mathrm{M} \mathrm{NaOH}$. After rinsing with de-ionized water, the $\mathrm{MnO}_{\mathrm{x}}$ coated $3 \mathrm{D} \mathrm{Al}$ samples were placed into the vanadyl sulfate solution and oxidized potentiostatically at $+1 \mathrm{~V}$ (vs. $\mathrm{Ag} / \mathrm{AgCl}$ ) for approximately $130 \mathrm{~s}$ resulting in a charge of $0.110 \mathrm{C}$. A Pt wire and an $\mathrm{Ag} / \mathrm{AgCl}$ electrode were used as counter and reference electrodes, respectively. The vanadium oxide coated $3 \mathrm{D}$ Al samples were finally annealed in air at $400^{\circ} \mathrm{C}$ for 10 hours.
Sol-gel synthesis. - To obtain a $\mathrm{V}_{2} \mathrm{O}_{5}$ reference sample for the structural analyzes of the electrodeposited vanadium oxide coatings a sol-gel based deposition method ${ }^{29,30}$ was also utilized. In this approach, the $200 \mathrm{~nm}$ diameter $\mathrm{Al}$ nanorods were first soaked with a $50 \mathrm{mM}$ V-oxytriisopropoxide (Sigma Aldrich) solution in anhydrous 1-methyl-2-pyrrolidinone (NMP) (Sigma Aldrich) by applying 120 $\mu \mathrm{L}$ of the precursor solution on the nanorod sample. To avoid any reaction between the V-oxytriisopropoxide and water ${ }^{30}$ before the wetting and infiltration of the $\mathrm{Al}$ substrate, this procedure was carried out in an Ar-filled glove box $\left(\mathrm{H}_{2} \mathrm{O}\right.$ and $\left.\mathrm{O}_{2}<1 \mathrm{ppm}\right)$. The impregnated sample was finally heat-treated in air for 10 hours at $400^{\circ} \mathrm{C}$ to obtain a coating of crystalline $\mathrm{V}_{2} \mathrm{O}_{5}$ on the $\mathrm{Al}$ microrods.

Structural and elemental characterization.- The surface morphology and the elemental composition of the deposits were studied with a Zeiss LEO 1550 scanning electron microscope (SEM) equipped with an energy dispersive X-ray (EDX) detector (Oxford Instruments). The surfaces of all electrodeposited vanadium oxide films were further investigated by X-ray photoelectron spectroscopy (XPS), by means of a Physical Systems Quantum 2000 spectrometer using monochromatic $\mathrm{Al} \mathrm{K}_{\alpha}$ radiation. The recorded spectra were calibrated in energy with reference to the $\mathrm{C} 1 \mathrm{~s}$ peak at a binding energy of $285.0 \mathrm{eV}$. Structural phase information was obtained by X-ray diffraction (XRD) measurements using a Siemens D5000 diffractometer utilizing a monochromatic $\mathrm{Cu} \mathrm{K}$ radiation source. The coatings were also studied by Raman micro-spectroscopy at room temperature employing a Renishaw inVia Raman microscope equipped with different excitation sources, i.e. $532 \mathrm{~nm}$ and $785 \mathrm{~nm}$ laser diodes (max power $500 \mathrm{~mW}$ ) and a $633 \mathrm{~nm} \mathrm{He} / \mathrm{Ne}$ laser (max power $50 \mathrm{~mW}$ ). The applied power was set to $1 \%$ for all the excitations at the different wavelengths. Fifty cumulative scans with an individual acquisition time of $50 \mathrm{~s}$ were collected for the spectra. The extent of aluminum corrosion during the vanadium oxidation on the bare $3 \mathrm{D} \mathrm{Al}$ substrates was evaluated by determinations of the aluminum concentration in the electrolytes with inductively coupled plasma optical emission spectrometry (ICP-OES - Spectro, Cirros CCD). The analyzes were carried out on samples of the vanadyl sulfate electrolyte taken before as well as after the vanadium oxide deposition.

Electrochemical characterizations. - To estimate the amount of electrodeposited vanadium oxide, electrochemical studies of the vanadium oxide coated nanostructured electrodes were performed using polymer coated aluminum pouch (i.e. "coffee-bag") cells which were assembled in an Ar-filled glove box $\left(\mathrm{H}_{2} \mathrm{O}<1 \mathrm{ppm}\right)$. Prior to assembly, the $3 \mathrm{D}$ electrodes were dried in vacuum at $120^{\circ} \mathrm{C}$ for five hours. The pouch cells comprised a vanadium oxide-coated $3 \mathrm{D}$ Al substrate with a $\mathrm{MnO}_{\mathrm{x}}$ interlayer as the working electrode and a $\mathrm{Li}$ metal foil as a combined counter and reference electrode. Approximately $50 \mu \mathrm{L}$ of an electrolyte containing $1 \mathrm{M} \mathrm{LiPF}_{6}$ dissolved in ethyl carbonate/diethyl carbonate (2:1) was used to soak a $15 \mu \mathrm{m}$-thick Solupor polymer separator placed between the two electrodes. The chronopotentiometric experiments were carried out by applying a constant current of $2 \mu \mathrm{A} / \mathrm{cm}^{2}$ in the voltage range between 1 and $4 \mathrm{~V}\left(\mathrm{vs} . \mathrm{Li}^{+} / \mathrm{Li}\right)$ using a Digatron BTS 600 galvanostat.

\section{Results and Discussion}

Electrodeposition of vanadium oxide on bare Al substrate.- As is seen in Figure 1 (red curve), oxidative electrodeposition of vanadium oxide on a planar aluminum substrate from a $\mathrm{pH} 2.70$ solution containing $0.1 \mathrm{M}$ vanadyl sulfate solution at $+1 \mathrm{~V}$ (vs. $\mathrm{Ag} / \mathrm{AgCl}$ ) resulted in a current density which increased almost linearly with time after an initiation time of about five seconds. This behavior is clearly not in agreement with the expected diffusion controlled oxidation of $\mathrm{VO}^{2+}$, nor with the presence of a resistance controlled oxidation. As the shape of the chronoamperogram in fact suggests that the electroactive area increased with time it is reasonable to assume that the phenomenon was coupled to corrosion of the aluminum surface as aluminum should undergo oxidation to $\mathrm{Al}^{3+}$ at this $\mathrm{pH}$ and potential. ${ }^{31}$ The five second 


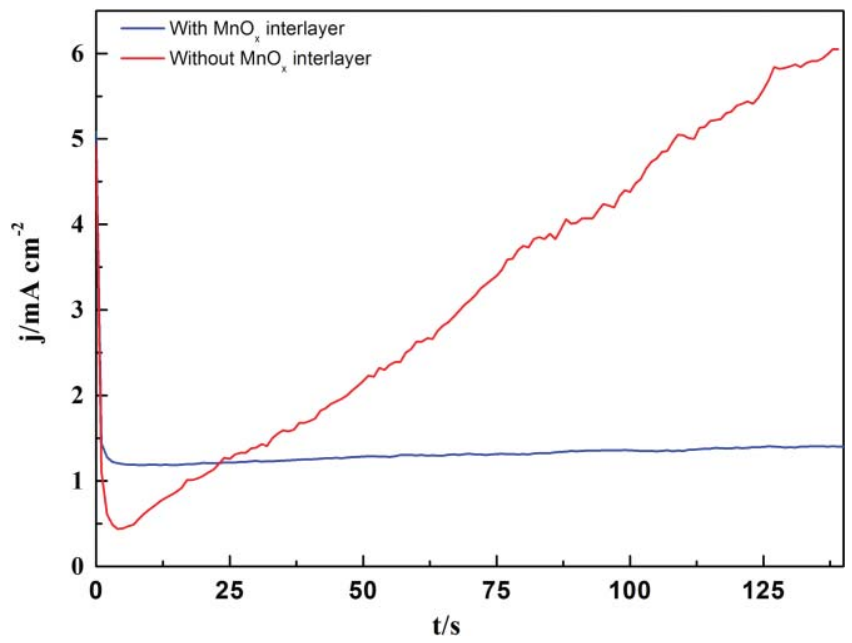

Figure 1. Potentiostatic oxidation of $0.1 \mathrm{M} \mathrm{VO}^{2+}$ at a potential of $+1 \mathrm{~V}$ (vs. $\mathrm{Ag} / \mathrm{AgCl}$ ) employing a bare planar $\mathrm{Al}$ substrate (red curve) and a $3 \mathrm{D} \mathrm{Al}$ substrate consisting of $\mathrm{Al}$ microrods coated with a thin layer of $\mathrm{MnO}_{\mathrm{x}}$ layer (blue curve), respectively.

delay seen prior to the onset of the corrosion can then be explained by the time required for the dissolution of the native $\mathrm{Al}_{2} \mathrm{O}_{3}$ layer initially present on the aluminum electrode. The corrosion hypothesis is further supported by the fact that ICP-OES measurements indicated that the aluminum concentration in the electrolyte increased from 0.3
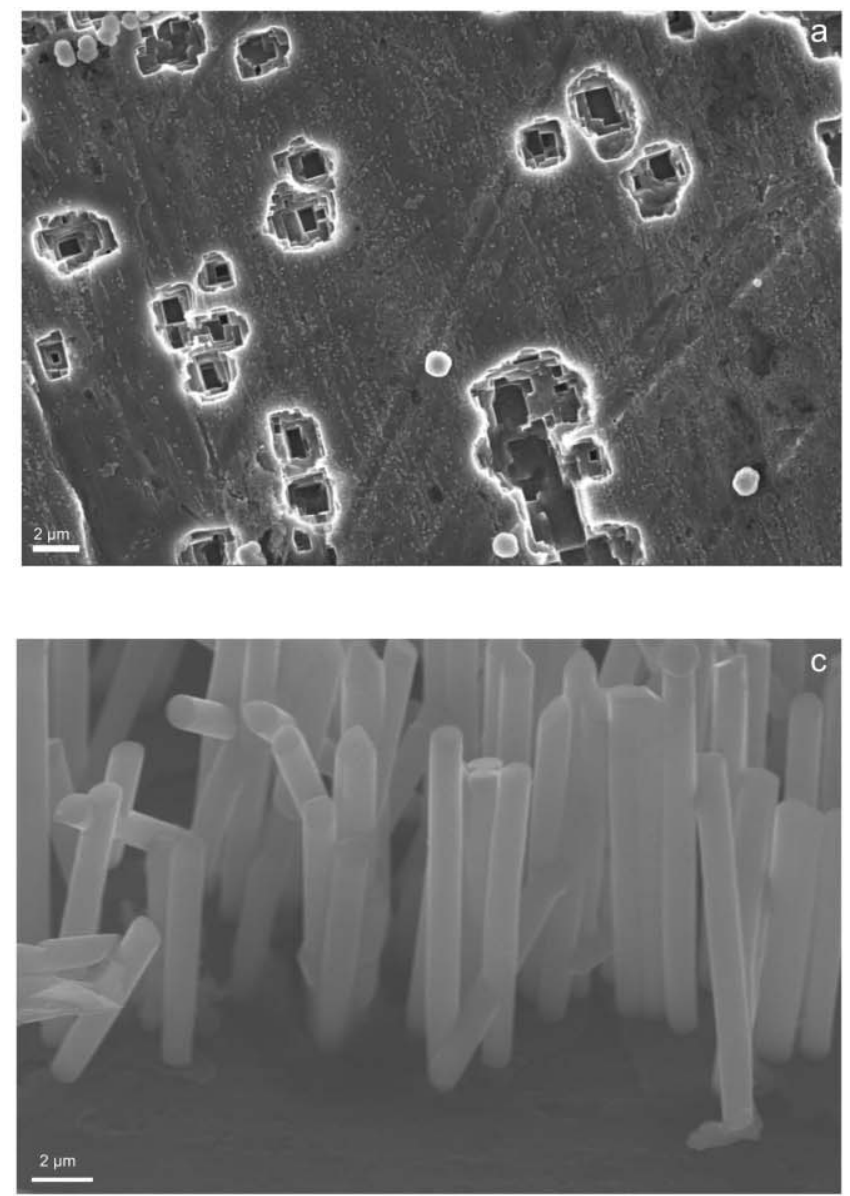

to $760 \mu \mathrm{g} / \mathrm{ml}$ during as a result of the oxidation reaction. As is seen in Figure 2a, depicting a SEM image of the planar Al substrate used in the experiment, corrosion pits were indeed found on the surface of the aluminum electrode. Since no vanadium oxide could be found on the aluminum surface after the oxidation (see the elemental analysis results in Figure 2b) the present results clearly show that it is difficult to deposit vanadium oxide on aluminum electrodes under the present experimental conditions (i.e. in the acidic solutions required for vanadium oxide deposition). As this problem can be expected to be even more accentuated for nanostructured $\mathrm{Al}$ substrates due to their intrinsically larger surface area, it is evident that other approaches need to be developed for electrochemical modifications of 3D aluminum electrodes.

Since one possibility to circumvent the corrosion problem would be to carry out the electrodeposition of vanadium oxide in solutions with higher $\mathrm{pH}$ values, it is important to understand the reactions taking place in the deposition process. The latter reactions have been discussed in previous work $\mathrm{w}^{24,25,27}$ and $\mathrm{V}_{2} \mathrm{O}_{5}$ deposition from $0.1 \mathrm{M}$ $\mathrm{VO}^{2+}$ solutions has been proposed ${ }^{24,25,27}$ to involve an initial oxidation of $\mathrm{VO}^{2+}$ followed by a precipitation of $\mathrm{V}_{2} \mathrm{O}_{5}$. For $\mathrm{pH}$ values larger than 1.8, but still sufficiently low to allow precipitation of $\mathrm{V}_{2} \mathrm{O}_{5}$, the following reactions were proposed (assuming a total vanadium concentration of $3.2 \mathrm{mM}$ ).

$$
10 \mathrm{VO}^{2+}+18 \mathrm{H}_{2} \mathrm{O} \rightarrow \mathrm{H}_{2} \mathrm{~V}_{10} \mathrm{O}_{28}^{4-}+34 \mathrm{H}^{+}+10 e^{-}
$$

$$
\mathrm{H}_{2} \mathrm{~V}_{10} \mathrm{O}_{28}^{4-}+4 \mathrm{H}^{+} \rightarrow 5 \mathrm{~V}_{2} \mathrm{O}_{5}+3 \mathrm{H}_{2} \mathrm{O}
$$
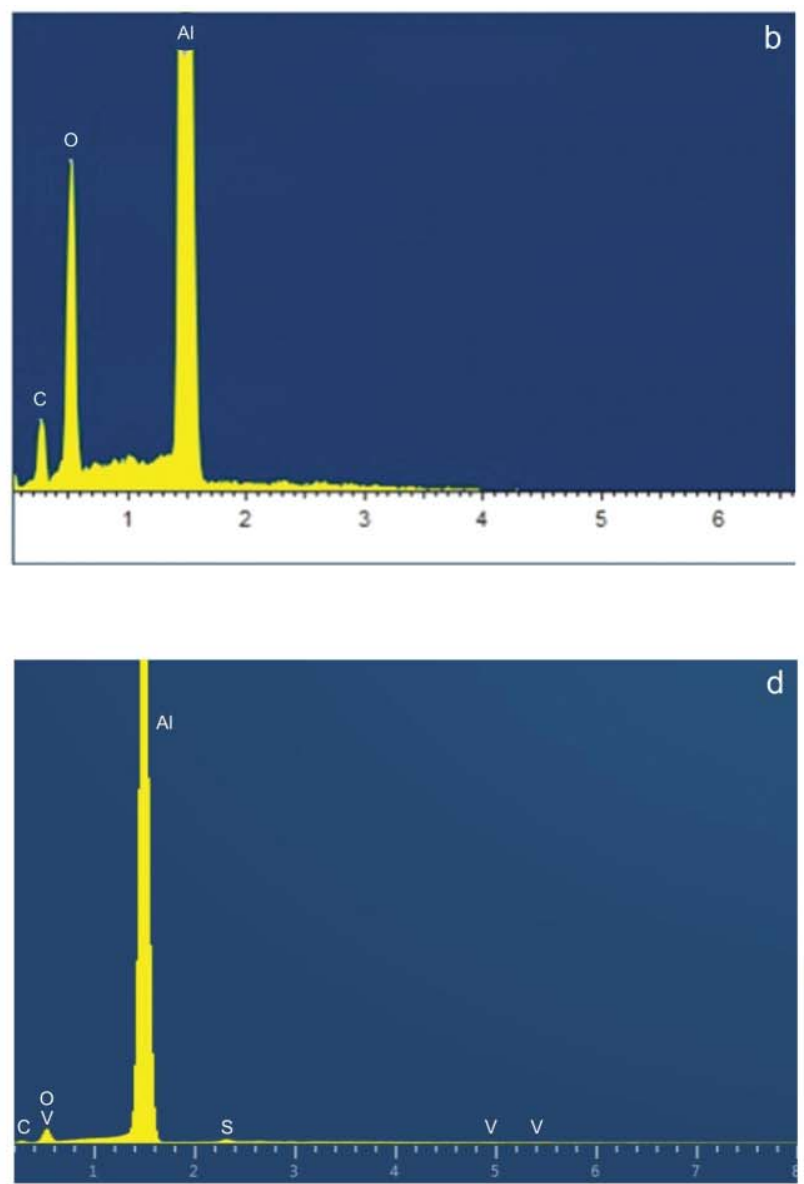

Figure 2. SEM micrographs ( $(\mathrm{a}, \mathrm{c})$ and corresponding EDS spectra $(\mathrm{b}, \mathrm{d})$ for a bare planar Al substrate $(\mathrm{a}, \mathrm{b})$ and a $\mathrm{MnO}_{\mathrm{x}}$-coated $3 \mathrm{D}$ Al substrate (c, d) subjected to oxidation at $+1 \mathrm{~V}(\mathrm{vs}$. $\mathrm{Ag} / \mathrm{AgCl})$ in a solution of $0.1 \mathrm{M} \mathrm{VO}^{2+}$. 
For $\mathrm{pH}$ values below 1.8 the following reactions were, on the other hand, proposed ${ }^{24,25,27}$ to take place.

$$
\mathrm{VO}^{2+}+\mathrm{H}_{2} \mathrm{O} \rightarrow \mathrm{VO}_{2}^{+}+2 \mathrm{H}^{+}+e^{-}
$$

$$
2 \mathrm{VO}_{2}^{+}+\mathrm{H}_{2} \mathrm{O} \rightarrow \mathrm{V}_{2} \mathrm{O}_{5}+2 \mathrm{H}^{+}
$$

Thermodynamic data ${ }^{24,25,27}$ further indicate that precipitation of $\mathrm{V}_{2} \mathrm{O}_{5}$ from a $0.1 \mathrm{M} \mathrm{VO}^{2+}$ solution only is possible in a $\mathrm{pH}$ region between about 0.3 and 3.4. Although a direct deposition of $\mathrm{V}_{2} \mathrm{O}_{5}$ should be possible according to the reaction below, previous results obtained by Potiron et al. ${ }^{24}$ suggest that this is less likely.

$$
2 \mathrm{VO}^{2+}+3 \mathrm{H}_{2} \mathrm{O} \rightarrow \mathrm{V}_{2} \mathrm{O}_{5}+6 \mathrm{H}^{+}+2 e^{-}
$$

Irrespective the $\mathrm{V}_{2} \mathrm{O}_{5}$ deposition mechanism assumed it is clear that the deposition only takes place in a rather narrow $\mathrm{pH}$ region and that the local $\mathrm{pH}$ at the electrode is expected to decrease further during the deposition. Since it should be possible to stabilize the native oxide layer on the aluminum substrate by increasing the $\mathrm{pH}$ of the electrolyte, a study of the influence of the $\mathrm{pH}$ on the deposition of vanadium oxide was therefore carried out. It was, however, found that the $\mathrm{pH}$ could only be increased to about 3.5 due to the onset of the precipitation of $\mathrm{VO}_{2}$ according to the following reaction.

$$
\mathrm{VO}^{2+}+\mathrm{H}_{2} \mathrm{O} \rightarrow \mathrm{VO}_{2}+2 \mathrm{H}^{+}
$$

Electrodeposition carried out in the $\mathrm{pH}$ range between 1.6 and 3.5 likewise proved unsuccessful as was confirmed by EDS analyzes of the aluminum surfaces which did not show any vanadium peaks after the deposition. It can therefore be inferred that aluminum corrosion prevented the depositions and that a new strategy consequently would be required for the oxidative electrodeposition of vanadium oxide on aluminum substrates from acidic aqueous solutions. This approach should be straightforward and versatile and also enable effective coatings of nanostructured 3D Al substrates. In the following sections, such an approach will be described based on the use of protecting layers initially deposited on the aluminum surfaces.

Electrodeposition of a protective $\mathrm{MnO}_{x}$ layer- - One way to circumvent the problems associated with the corrosion of the aluminum substrates during the deposition of vanadium oxide (or any other functional layer) could be to first coat the aluminum surfaces with an initial layer that is protecting enough to allow the subsequent deposition of vanadium oxide. This intermediate layer should clearly be stable in the acidic and oxidative environment required for vanadium oxide electrodeposition and it would also be convenient if the protective layer could be directly formed by electrodeposition, maintaining the coating procedure simple and cost-effective. In the present work, a layer of manganese oxide $\left(\mathrm{MnO}_{\mathrm{x}}\right)$ was therefore chosen since at least $\mathrm{MnO}_{2}$ should be stable in the $\mathrm{pH} /$ voltage window required for vanadium oxide deposition and as the deposition of the $\mathrm{MnO}_{\mathrm{x}}$ layer readily can be carried out by cathodic electrodeposition. ${ }^{28}$ In this way oxidation of the $\mathrm{Al}$ substrate is also avoided and an all-electrochemical deposition approach is obtained. As the manganese oxide interlayer can undergo phase transformations, due to aging effects and oxidation during the subsequent vanadium oxide electrodeposition, it will therefore be referred to as $\mathrm{MnO}_{\mathrm{x}}$ in this study. As will be demonstrated below the main purpose of this $\mathrm{MnO}_{\mathrm{x}}$ layer is thus merely to slow down the corrosion of aluminum sufficiently initially to allow electrodeposition of vanadium oxide on the aluminum microrods. The $\mathrm{MnO}_{\mathrm{x}}$ layer does hence not need to form a perfect conformal layer on the microrods as long as it allows vanadium oxide deposition to take place since the latter layer subsequently will act as a corrosion preventing layer.

The cathodic electrodeposition of $\mathrm{MnO}_{\mathrm{x}}$ was carried out from a solution containing $5 \mathrm{mM} \mathrm{MnCl}$, and $0.4 \mathrm{~g} / \mathrm{L}$ polyethylenimine (PEI) in 5 vol. $\%$ water and $95 \%$ ethanol, employing a pulsed chronopotentiometric approach (see the Experimental section). An operating potential of $-7.6 \mathrm{~V}$ (vs. $\mathrm{Ag} / \mathrm{AgCl}$ ) was observed during the synthesis indicating a significant iR-drop in the cell due to the poor conductivity of the ethanol based electrolyte. Water reduction is the most likely reaction taking place as oxygen reduction was unlikely to be able to sustain the applied current density and as reduction of $\mathrm{Mn}^{2+}$ was implausible since precipitation of $\mathrm{MnO}_{\mathrm{x}}$ was detected by EDS. As is seen from the reactions below, the deposition is consequently based on a precipitation of $\mathrm{Mn}(\mathrm{OH})_{2}$ due to the increased local $\mathrm{pH}$ caused by the reduction of water.

$$
\begin{gathered}
2 \mathrm{H}_{2} \mathrm{O}+2 e^{-} \rightarrow 2 \mathrm{OH}^{-}+\mathrm{H}_{2}(g) \\
2 \mathrm{OH}^{-}+\mathrm{Mn}^{2+} \rightarrow \mathrm{Mn}(\mathrm{OH})_{2}
\end{gathered}
$$

The $\mathrm{Mn}(\mathrm{OH})_{2}$ then undergoes transformation into $\mathrm{MnO}_{\mathrm{x}}$ upon loss of water. One problem with this deposition method is, however, that the thickness of the $\mathrm{MnO}_{\mathrm{x}}$ layer cannot be directly calculated from the deposition charge since there is no immediate correlation between the water reduction charge and the amount of deposited $\mathrm{Mn}(\mathrm{OH})_{2}$. In a previous study ${ }^{28}$ it was, nevertheless, demonstrated that the thickness of the $\mathrm{MnO}_{\mathrm{x}}$ layer formed was linearly dependent on the deposition time which is why it is reasonable to assume that the deposition time can be used as a measure of the thickness of the $\mathrm{MnO}_{\mathrm{x}}$ layer. A rough estimate of the $\mathrm{MnO}_{\mathrm{x}}$ layer thickness can then be obtained based on the previously reported ${ }^{28}$ deposition rate and the present electroactive area of $1.13 \mathrm{~cm}^{2}$ obtained after examining Figure 2c. The latter figure indicates that approximately 13 microrods (with average height and diameter of about $8 \mu \mathrm{m}$ and $1 \mu \mathrm{m}$, respectively) were found on an area of $40 \mu \mathrm{m}^{2}$, yielding a total area of $1.13 \mathrm{~cm}^{2}$ for the $0.5 \mathrm{~cm}^{2}$ footprint area. Based on this, deposition for 20 s (i.e. about 200 cycles) was expected to give rise to an approximately $40 \mathrm{~nm}$ thick $\mathrm{MnO}_{\mathrm{x}}$ layer although it should be pointed out that it is not essential to know the exact composition or thickness of the film in this case as long as the $\mathrm{MnO}_{\mathrm{x}}$ layer protects the aluminum surface sufficiently during the initial vanadium oxide deposition.

Electrodeposition of vanadium oxide on $\mathrm{MnO}_{x}$ coated $3 \mathrm{D} \mathrm{Al}$ substrate.- As is seen from the blue curve in Figure 1, potentiostatic oxidation of $\mathrm{VO}^{2+}$ on the $\mathrm{MnO}_{\mathrm{x}}$ coated 3D aluminum substrate gave rise to a steady state current density of about $1.3 \mathrm{~mA} / \mathrm{cm}^{2}$, suggesting that the $\mathrm{MnO}_{\mathrm{x}}$ layer inhibited the aluminum corrosion sufficiently to enable deposition of vanadium oxide. SEM/EDS investigations (see Figure 2c) after the deposition revealed that the Al microrods remained intact indicating that the $\mathrm{MnO}_{\mathrm{x}}$ coating provided sufficient corrosion protection of the aluminum microrods. This also suggests that the $\mathrm{V}_{2} \mathrm{O}_{5} / \mathrm{MnO}_{\mathrm{x}}$ hybrid thin film coated the 3D architecture sufficiently well although traces of agglomeration caused by trace amounts of electrolyte could be seen between the microrods. The latter micrograph was obtained at a 45 degree angle to fully show the characteristics of the microrods, including the maximum rod height which was about $11 \mu \mathrm{m}$. An EDS analysis of the Al microrods, see Figure 2d, showed characteristic $\mathrm{O}$ and $\mathrm{V}$ peaks in addition to the peak due to the $\mathrm{Al}$ substrate. A small sulfur peak was also observed most likely as a result of traces of the sulfate based salt. The fact that the EDS analysis failed to detect manganese, is not surprising considering that $\mathrm{K}$-shell excitation peaks for $\mathrm{O}, \mathrm{V}$ and $\mathrm{Mn}$ overlap making detection of manganese oxide thin films difficult by EDS. The fact that no signs of aluminum corrosion were found both in the micrograph in Figure 2c, or in the chronoamperogram (see Figure 1), however, clearly indicate the presence of a sufficiently protecting $\mathrm{MnO}_{\mathrm{x}}$ film and that vanadium oxide could be electrodeposited on these $\mathrm{MnO}_{\mathrm{x}}$ modified microrods without compromising the integrity of the $\mathrm{Al}$ support. Experiments were carried out to determine the minimal $\mathrm{MnO}_{\mathrm{x}}$ thickness required to provide sufficient protection against $\mathrm{Al}$ corrosion during the vanadium oxidation. It was found that $\mathrm{anO}_{\mathrm{x}}$ deposition time of at least 20 s (i.e. 200 cycles) was required.

The attainment of a steady state current for the $\mathrm{MnO}_{\mathrm{x}}$ coated substrate in Figure 1 is somewhat unexpected since the oxidation of $\mathrm{VO}^{2+}$ should be diffusion controlled and since a comparison with the chronoamperogram obtained in the absence of the MnOx layer indicates that the current was unlikely to have been controlled by the resistance of the electrolyte. The resistance of an approximately $20 \mathrm{~nm}$ 
thick layer of $\mathrm{MnO}_{\mathrm{x}}$ can likewise be neglected as it is well-known ${ }^{28}$ that these kinds of $\mathrm{MnO}_{\mathrm{x}}$ films do not yield resistance controlled voltammograms. More importantly, the electrochemical experiments carried out to determine the amount of vanadium oxide deposited on the electrode (see below), indicate that less than $10 \%$ of the deposition charge was in fact used to generate the vanadium oxide coating. Based on this finding it is immediately clear that the steady state oxidation current cannot be explained based on the deposition of vanadium oxide alone. As the deposition process is believed to involve oxidation of $\mathrm{VO}^{2+}$ followed by precipitation of $\mathrm{V}_{2} \mathrm{O}_{5}$ (see reaction 1 and 2), this effect could be explained by a significant amount of vanadium (V) species being lost from the electrode surface without undergoing precipitation. This should, however, give rise to a diffusion controlled current rather than the steady state current seen in Figure 1 . At $+1 \mathrm{~V}$ (vs. $\mathrm{Ag} / \mathrm{AgCl}$ ) it is also possible that the $\mathrm{MnO}_{\mathrm{x}}$ film undergoes oxidation as $\mathrm{MnO}_{2}$ is the thermodynamically stable form at this potential. ${ }^{31}$ This surface confined reaction should, however, mainly contribute to the current at short times due to the thin layer of $\mathrm{MnO}_{\mathrm{x}}$ and can therefore not explain the steady state current. A more likely explanation involves oxidation of $\mathrm{VO}^{2+}$ generating vanadium $(\mathrm{V})$ oxide which subsequently oxidizes water in a reaction regenerating $\mathrm{VO}^{2+}$ according to the following reactions.

$$
4 V^{I V} \rightarrow 4 V^{V}+4 e^{-}
$$

$$
4 \mathrm{~V}^{V}+2 \mathrm{H}_{2} \mathrm{O} \rightarrow 4 \mathrm{~V}^{I V}+\mathrm{O}_{2}(g)+4 H^{+}
$$

This catalytic (i.e. $\mathrm{EC}_{\mathrm{i}}{ }^{\prime}$ ) model is in good agreement with previous findings ${ }^{21,22}$ as well as the fact that the thermodynamically required potential for oxidation of water is $+0.87 \mathrm{~V}$ (vs. $\mathrm{Ag} / \mathrm{AgCl}$ ) at $\mathrm{pH}$ 2.7 whereas the oxidation was carried out at a potential of $+1 \mathrm{~V}$ (vs. $\mathrm{Ag} / \mathrm{AgCl}$ ). According to this hypothesis, the steady state current would hence be controlled by the rate by which $\mathrm{V}^{\mathrm{IV}}$ is regenerated via reaction 10 .

XPS, Raman and XRD analyzes of the manganese oxide/vanadium oxide coatings. - Further analyzes of the pristine (i.e. non-annealed) electrodeposited vanadium oxide film using XPS confirmed the presence of vanadium oxide as is seen from the $V 2 p_{3 / 2}$ spectra in Figure 3 . As the analysis of the $V 2 p_{3 / 2}$ spectrum according to, ${ }^{32}$ indicated the presence of about $45 \% \mathrm{~V}^{\mathrm{V}}$ and $55 \% \mathrm{~V}^{\mathrm{IV}}$ it is clear that the deposition gives rise to a material containing a mixture of vanadium

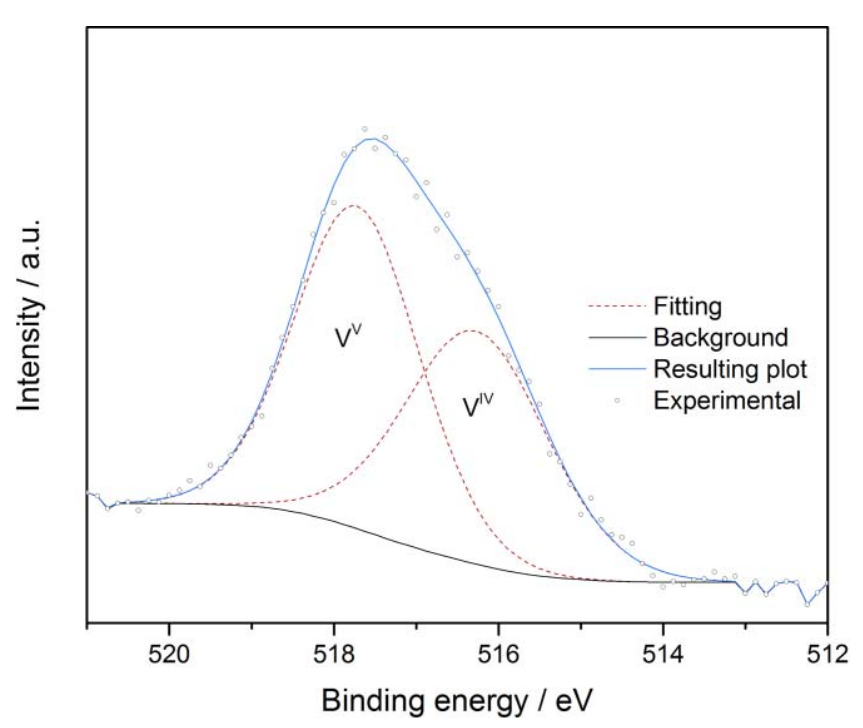

Figure 3. XPS data depicting V2 $\mathrm{p}_{3 / 2}$ spectra for the electrodeposited vanadium oxide film on manganese coated $\mathrm{Al}$ microrods. The fitted curves represent the estimated contributions from $\mathrm{V}^{\mathrm{V}}$ and $\mathrm{V}^{\mathrm{IV}}$. oxides in good agreement with previous findings. ${ }^{21,22}$ As demonstrated by Potiron et al. ${ }^{24}$ and $\mathrm{Li}$ et al., ${ }^{25}$ the $\mathrm{V}^{\mathrm{V}} / \mathrm{V}^{\mathrm{IV}}$ ratio is potential dependent with higher potentials yielding higher concentrations of $\mathrm{V}^{\mathrm{V}}$. The latter can be explained by the fact that the deposition rate increases with increasing anodic potential and by assuming that the deposited vanadium $(\mathrm{V})$ oxide undergoes reduction in which $\mathrm{H}^{+}$is intercalated into the structure (compare reaction 10). Precipitation of vanadium (IV) oxide, on the other hand, seems unlikely at the present $\mathrm{pH}$ values based on thermodynamic data. ${ }^{24,27}$ No traces of manganese oxide were detected in the outermost surface of the 3D substrate, as can be expected considering that the vanadium oxide film was deposited on top of the manganese oxide layer. Sputtering of the surface to analyze the underlying structures was not pursued due to the complex nature of the nanostructured substrate which makes homogeneous milling very difficult. Instead, the underlying coating of the 3D architecture was investigated using surface enhanced Raman scattering (SERS) due to localized surface plasmon resonance. Although this effect typically is used for noble metals (e.g. Au and Ag), it can also be used for aluminum ${ }^{33}$ as will be described below.

The electrodeposited coatings were also studied with XRD after annealing at $400^{\circ} \mathrm{C}$ in air. The annealing was carried out to increase the crystallinity of the coatings prior to the electrochemical Li-ion cycling experiments employed to determine the amount of vanadium oxide deposited. The XRD data (see Figure 4) did not provide any evidence for the presence of crystalline $\mathrm{MnO}_{2}$, most likely due to the fact that the thin manganese oxide film still was amorphous or nanocrystalline despite the annealing step. Since there was no vanadium oxide peaks the data further suggest that the vanadium oxide likewise was amorphous or nanocrystalline. The electrodeposited sample, however, exhibited a large peak at $22.3^{\circ}$ with similar features as those previously seen $^{5}$ for bare $\mathrm{Al}$ rod substrates (see Figure S1 in supporting information). It can therefore be concluded that the XPS and XRD data indicate that the electrodeposition gave rise to amorphous or nanocrystalline vanadium oxide (e.g. $\mathrm{V}_{2} \mathrm{O}_{5}$ ). XRD analyzes of a sol-gel synthesized 3D vanadium oxide coating carried out after analogous annealing in air at $400^{\circ} \mathrm{C}$, on the other hand showed that the impregnation of the $3 \mathrm{D}$ aluminum substrate with a V-oxytriisopropoxide solution ${ }^{30}$ can be used to yield $\mathrm{V}_{2} \mathrm{O}_{5}$ through a reaction involving atmospheric water during the heat-treatment. As can be seen in Figure 5, the sol-gel approach resulted in the generation of a sparse distribution of vanadium oxide nanoparticles on the aluminum substrate. The diffractogram for the sol-gel coating depicted

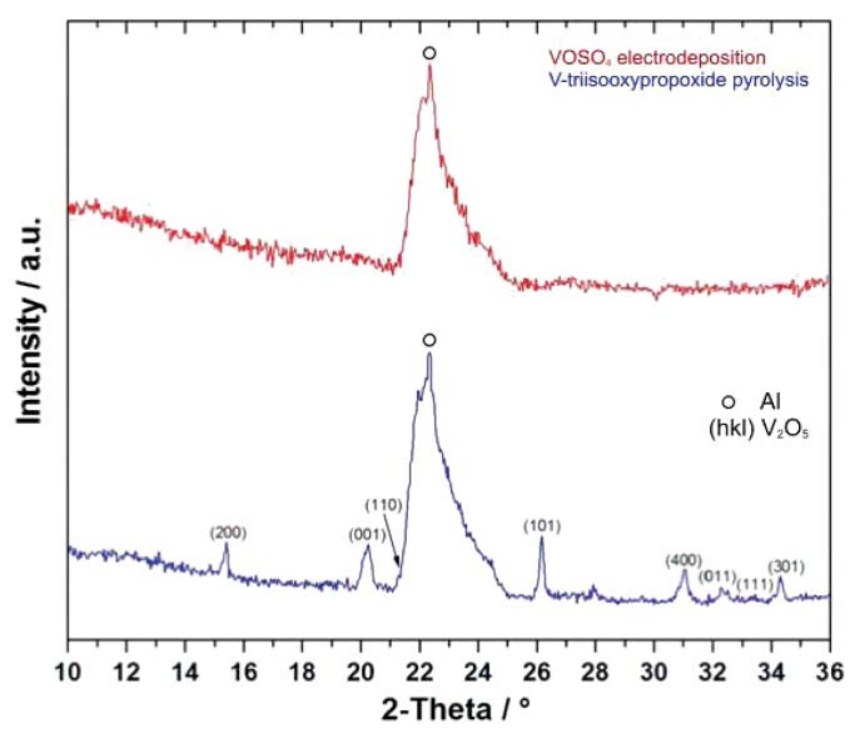

Figure 4. XRD data depicting diffractogram for 3D Al substrates coated with vanadium oxide by electrodeposition (red curve) and the sol-gel approach (blue curve), respectively. 


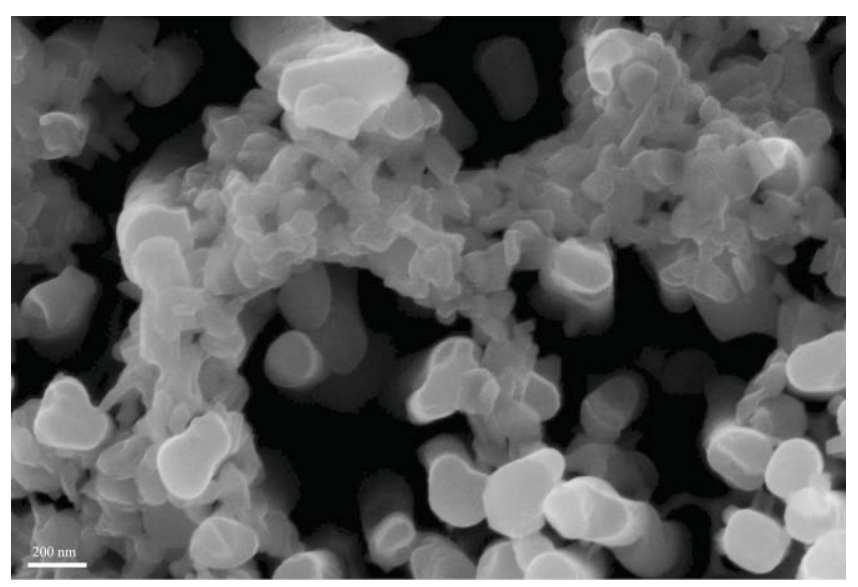

Figure 5. SEM micrograph showing the sol-gel obtained $\mathrm{V}_{2} \mathrm{O}_{5}$ deposit manufactured by infiltration of a 3D Al substrate with a V-oxytriisopropoxide solution, followed by heat-treatment in air at $400^{\circ} \mathrm{C}$ for 10 hours.

in Figure 4 clearly demonstrates that crystalline $\mathrm{V}_{2} \mathrm{O}_{5}$ was obtained with the sol-gel approach (the diffraction peaks match those of the vanadium pentoxide lattice structure (JCPDF No. 86-2248)). As for the electrodeposited sample, a major peak was observed at $22.3^{\circ}$ also for the sol-gel reference sample. The latter supports the hypothesis that this feature originated from the nanostructured $\mathrm{Al}$ substrate itself.

Raman spectra were further collected for the annealed electrodeposited sample and these measurements were optimized to activate the SERS effect imposed by the nanostructured Al substrate (see Figure 6). The SERS effect typically enables the detection of tiny amounts of species present in the outermost surface layer, due to the localized plasmon excitations along the metallic substrate. ${ }^{33,34}$ Various spectra were collected using excitation with laser light with different wavelengths (i.e. 532, 633 and $785 \mathrm{~nm}$ ). Due to considerable fluorescence, the spectrum obtained with the $532 \mathrm{~nm}$ laser source was, however, excluded from Figure 6, which consequently only shows the spectra collected for excitation at $633 \mathrm{~nm}$ (red curve) and 785 nm (blue curve). Several broadband features were observed around 282,458 and $571 \mathrm{~cm}^{-1}$ in addition to the most prominent peak at 647 $\mathrm{cm}^{-1}$ when using the infrared laser source. Previous Raman studies

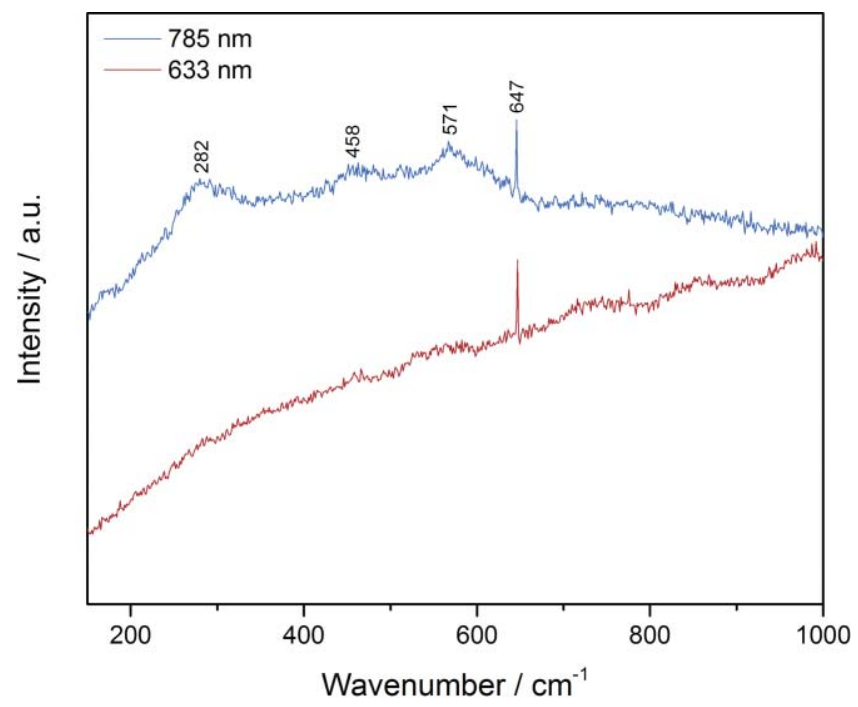

Figure 6. SERS spectra obtained for the $\mathrm{MnO}_{\mathrm{x}}$-coated $3 \mathrm{D} \mathrm{Al}$ support covered with vanadium oxide by electrodeposition. The spectra were obtained using 633 $\mathrm{nm}$ (red curve) and $785 \mathrm{~nm}$ (blue curve) excitation wavelengths, respectively. The most prominent $\mathrm{MnO}_{\mathrm{x}}$ features observed with the $785 \mathrm{~nm}$-laser source are marked in the figure. on manganese oxide have shown similar peaks for $\mathrm{MnO}_{2},{ }^{35,36}$ where the most intense peak typically was observed around $640-650 \mathrm{~cm}^{-1}$, in good agreement with the present results. The slight peak offsets compared to previously reported results ${ }^{35,36}$ can be explained based on the typical broad peaks observed for the various manganese oxide structures having different stoichiometries and by also taking into account the fact that different excitation wavelengths were used. The strongest peak at $647 \mathrm{~cm}^{-1}$ was thus hardly observed with the $633 \mathrm{~nm}$ laser source (red curve) and the broadband features also appeared very weak, if not absent. Furthermore, no vanadium oxide signatures were detected, as can be expected, since the SERS effect primarily should involve a few nanometer thin layer close to the aluminum surface and as the outermost vanadium oxide layer did not show any evident crystallinity to favor detection in the absence of a strong local signal enhancement.

The results of the XPS, XRD and Raman experiments consequently indicate that the annealed electrodeposited coating contained amorphous or nanocrystalline vanadium oxide (e.g. $\mathrm{V}_{2} \mathrm{O}_{5}$ ) situated on top of a thin $\mathrm{MnO}_{\mathrm{x}}$ film. As the amount of deposited vanadium oxide was very difficult to obtain from the deposition charge, the SEM micrographs and the spectroscopic data, additional electrochemical experiments were carried out in which the vanadium oxide coated substrates were used as cathodes in Li-ion battery cells. The results of these experiments will be described in the next section.

Chronopotentiometric studies of the vanadium oxide coatings as Li-ion cathode materials. - To estimate the amount of electrodeposited vanadium oxide on the $\mathrm{Al}$ microrods and to study the electrochemical behavior of the material in a lithium ion battery concept, chronopotentiometric experiments were carried out with the vanadium oxide coated substrate as the cathode in a thin layer Li-ion battery cell. As can be seen in Figure 7, the material was rapidly reduced yielding a cell voltage of $1 \mathrm{~V}$ (vs. $\mathrm{Li}^{+} / \mathrm{Li}$ ) upon $\mathrm{Li}^{+}$insertion into the vanadium oxide starting from an open circuit potential (OCP) of $2.5 \mathrm{~V}$ (vs. $\mathrm{Li}^{+} / \mathrm{Li}$ ). The subsequent (i.e. first) charging step required a significantly larger charge, i.e. $3.4 \mu \mathrm{Ah} / \mathrm{cm}^{2}$ or $13 \mathrm{mC}$ and the latter charge was taken as a measure of the amount of vanadium oxide since the first discharge capacity clearly was too low, most likely due to significant self-discharge during the time required for the assembly of the cell and its connection to the galvanostat. The latter hypothesis is supported

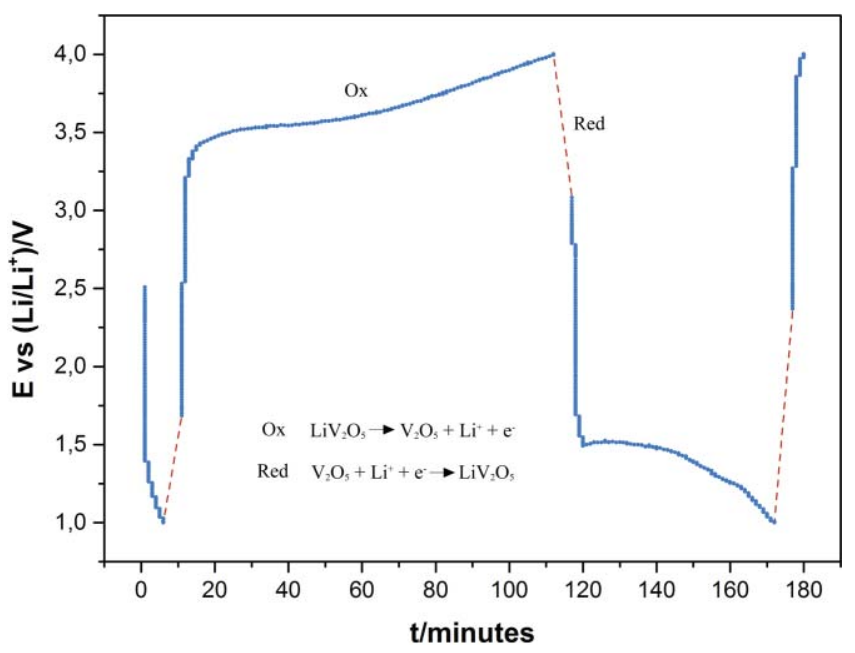

Figure 7. Chronopotentiograms displaying the electrochemical behavior of an electrodeposited vanadium oxide coated $3 \mathrm{D}$ Al substrate with an intermediate $\mathrm{MnO}_{\mathrm{x}}$ layer when used as a cathode material in a Li-ion micro battery. The 3D electrode was cycled between 1 and $4 \mathrm{~V}\left(\mathrm{vs} . \mathrm{Li}^{+} / \mathrm{Li}\right)$ using a current density of $2 \mu \mathrm{A} / \mathrm{cm}^{2}$ employing a coffee-bag cell comprising a Li combined counter and reference electrode. The dashed red segments indicate the changes in the cell voltage as a result of the five-minute pauses employed between the charge and discharge steps. 
by the too low initial OCP value compared to the $3.4 \mathrm{~V}\left(\mathrm{vs} . \mathrm{Li}^{+} / \mathrm{Li}\right.$ ) previously reported by Whittingham ${ }^{37}$ for the $\mathrm{V}_{2} \mathrm{O}_{5} / \mathrm{LiV}_{2} \mathrm{O}_{5}$ redox couple. The initial charge capacity of $13 \mathrm{mC}$ corresponds to a vanadium oxide coating with an average thickness of about $30 \mathrm{~nm}$ on the nanostructured $\mathrm{Al}$ substrate or a total amount of $\mathrm{V}_{2} \mathrm{O}_{5}$ of about 11.4 $\mu \mathrm{g}$ (based on an area of $1.13 \mathrm{~cm}^{2}$ and a $\mathrm{V}_{2} \mathrm{O}_{5}$ density of $3.36 \mathrm{~g} / \mathrm{cm}^{3}$ ). It is hence clear that the total amount of electrodeposited $\mathrm{V}_{2} \mathrm{O}_{5}$ was at least three orders of magnitude smaller than the amounts typically used in Li-ion battery tests which explains the low total charge capacity obtained. While the protective manganese oxide layer in principle also could contribute to the observed charge this contribution is most likely small since the manganese oxide was covered by the vanadium oxide layer.

Considering the minute amount of electroactive material spread as a thin film on a relatively large area electrode in a thin layer cell, it is reasonable to expect significant self-discharge for $\mathrm{V}_{2} \mathrm{O}_{5}$, although such problems would not generally be noticed for larger amounts of active materials. As is indicated in Figure 7, a five minute pause was employed between the discharge and charge steps to study the selfdischarge effect in more detail. It is seen that the potential increased to $1.7 \mathrm{~V}$ (vs. $\mathrm{Li}^{+} / \mathrm{Li}$ ) during this wait period and that the potential increased rapidly up to $3.3 \mathrm{~V}$ (vs. $\mathrm{Li}^{+} / \mathrm{Li}$ ) once the charging was initiated, yielding a rather well-defined intercalation plateau prior to reaching the cutoff voltage of $4 \mathrm{~V}\left(\mathrm{vs} \mathrm{Li}^{+} / \mathrm{Li}\right)$. The latter plateau can be ascribed to oxidation of $\mathrm{V}^{\mathrm{IV}}$ to $\mathrm{V}^{\mathrm{V}}$ accompanied by a simultaneous release of one lithium ion, in good agreement with previous findings. ${ }^{18,37}$ During the subsequent discharge, the expected reduction plateau due to the reduction of $\mathrm{V}^{\mathrm{V}}$ to $\mathrm{V}^{\mathrm{IV}}$ was not observed. Instead, a potential of $3.07 \mathrm{~V}$ was found after the five minute waiting period suggesting that the reduction $\left(\mathrm{V}^{\mathrm{V}}\right.$ to $\left.\mathrm{V}^{\mathrm{IV}}\right)$ had in fact already taken place as a result of self-discharge. Upon further discharge a rapid potential drop to $1.5 \mathrm{~V}$ was consequently seen indicating reduction of $\mathrm{V}^{\mathrm{IV}}$ to $\mathrm{V}^{\mathrm{III}}$. Previous work by Nordlinder et al., ${ }^{18}$ has shown that $\mathrm{V}^{\mathrm{III}}$ can be formed at potentials around $2.0 \mathrm{~V}\left(\mathrm{vs} . \mathrm{Li}^{+} / \mathrm{Li}\right.$ ) and that this reaction is accompanied by a substantial structural reorganization of the host lattice resulting in an irreversible capacity loss. This phenomenon can therefore explain the lack of an intercalation plateau on the second charge cycle.

The chronopotentiometric Li-ion cycling experiments clearly show that the amount of electrodeposited vanadium oxide was of the order of $10 \mu \mathrm{g}$ distributed in the form of an approximately $30 \mathrm{~nm}$ coating on the $3 \mathrm{D}$ substrate and that this gives rise to significant self-discharge problems. More importantly, the results clearly show that the electrodeposition approach was successful as similar problems should be expected for most analogous 3D cathode materials unless the total amount of electroactive material is increased significantly by the use of surfaces with much higher surface area gain factors. In the present case, the surface area gain factor was only about 2.3 due to the relatively large diameter of the $\mathrm{Al}$ microrods. It is therefore reasonable to assume that the present electrodeposition approach, which circumvents the aluminum corrosion problem in acidic solutions, can indeed be used for the manufacturing of nanostructured aluminum substrates with functional coatings for use in e.g. 3D lithium microbatteries.

\section{Conclusions}

It has been demonstrated that electrodeposition of vanadium oxide on 3D aluminum substrates is possible in acidic solutions when using a nanometer thin intermediate $\mathrm{MnO}_{\mathrm{x}}$ layer electrodeposited on the $\mathrm{Al}$ microrods to prevent these from undergoing corrosion. The presence of vanadium oxide, containing a mixture of $\mathrm{V}^{\mathrm{V}}$ and $\mathrm{V}^{\mathrm{VI}}$, on top of a thin layer of manganese oxide is supported by XRD, XPS, EDS and Raman spectroscopy data. The results also indicate that the electrodeposition of vanadium $(\mathrm{V})$ oxide is complicated by the fact that the deposited $\mathrm{V}_{2} \mathrm{O}_{5}$ is a powerful oxidation agent able to oxidize water (and probably also non-aqueous electrolytes). The amount of deposited vanadium oxide could be estimated from experiments carried out with the vanadium oxide coated $\mathrm{MnO}_{\mathrm{x}} / \mathrm{Al}$ microrods as a cathode in a Li-ion battery. The latter results also demonstrate that self-discharge effects can be significant for 3D microbatteries when the total amount of active material is order of magnitudes smaller than those employed in conventional Li-ion batteries. The described allelectrochemical deposition approach constitutes a versatile method for the deposition of functional coatings on aluminum substrates providing new possibilities for inexpensive and versatile manufacturing of functional coatings, including the realization of advanced nanostructured systems for use in $\mathrm{Li}$-ion microbatteries.

\section{Acknowledgments}

The authors thank Sara Munktell and Solveig Böhme for valuable help with the XPS measurements as well as Maria Hahlin and Nils Nedfors for fruitful discussions regarding the analyzes of the XPS spectrum. Jonas Högström is also gratefully acknowledged for his help with the ICP-OES measurements. Financial support from The Swedish Research Council (VR. 2011-3506 and 2012-4681), The Swedish Energy Agency (STEM), Ångström Advanced Battery Center $(\AA \mathrm{ABC})$ and StandUp for Energy is also gratefully acknowledged.

\section{References}

1. K. Edström, D. Brandell, T. Gustafsson, and L. Nyholm, The Electrochemical Society Interface, 20, 41 (2011).

2. M. Roberts, P. Johns, J. Owen, D. Brandell, K. Edström, G. El Enany, C. Guery, D. Golodnitsky, M. Lacey, C. Lecoeur, H. Mazor, E. Peled, E. Perre, M. M. Shaijumon, P. Simon, and P.-L. Taberna, Journal of Materials Chemistry, 21, 9876 (2011)

3. P-L. Taberna, S. Mitra, P. Poizot, P. Simon, and J-M. Tarascon, Nature materials, 5 567 (2006).

4. T. Gao, G. Meng, Y. Wang, S. Sun, and L. Zhang, Journal of Physics: Condensed Matter, 14, 355 (2002)

5. G. Oltean, L. Nyholm, and K. Edström, Electrochimica Acta, 56, 3203 (2011)

6. E. Perre, L. Nyholm, T. Gustafsson, P.-L. Taberna, P. Simon, and K. Edström, Electrochemistry Communications, 10, 1467 (2008).

7. A. H. Whitehead and M. Schreiber, Journal of The Electrochemical Society, 152 A2105 (2005)

8. M. Sheffer, A. Groysman, and D. Mandler, Corrosion Science, 45, 2893 (2003).

9. T. Wan and Y. J. Tan, Materials Science and Engineering B, 132, 48 (2006).

10. D. Wang and G. P. Bierwagen, Progress in Organic Coatings, 64, 327 (2009).

11. B. Dunn, C.-J. Kim, and S. Tolbert, in 23rd IEEE International Conference on Micro Electro Mechanical Systems (MEMS 2010), p. 164, Hong Kong (2010).

12. R. W. Hart, H. S. White, B. Dunn, and D. R. Rolison, Electrochemistry Communications, 5, 120 (2003).

13. S. K. Cheah, E. Perre, M. Rooth, M. Fondell, A. Hårsta, L. Nyholm, M. Boman, T. Gustafsson, J. Lu, P. Simon, and K. Edström, Nano Letters, 9, 3230 (2009).

14. B. O'Reagan and M. Grätzel, Letters to Nature, 353, 737 (1991)

15. W. Wei, G. Oltean, T. Cheuk-Wai, K. Edström, F. Björefors, and L. Nyholm, Journal of Materials Chemistry A, 1, 8160 (2013).

16. S. Beke, Thin Solid FIlms, 519, 1761 (2011)

17. Y. Wang and G. Cao, Chemistry of Materials, 18, 2787 (2006).

18. S. Nordlinder, L. Nyholm, T. Gustafsson, and K. Edström, Chemistry of Materials, 18, 495 (2006).

19. X. Chen, E. Pomerantseva, P. Banerjee, K. Gregorczyk, R. Ghodssi, and G. Rubloff, Chemistry of Materials, 24, 1255 (2012)

20. C. R. Aita, Y. L. Liu, M. L. Kao, and S. D. Hansen, J. Appl. Phys., 60, 749 (1986)

21. T. N. Kennedy, R. Hakim, and Jd. Mackenzi, Mater. Res. Bull., 2, 193 (1967).

22. Z. S. El Mandouh and M. S. Selim, Thin Solid FIlms, 371, 259 (2000).

23. C.-M. Huang, C.-C. Hu, K.-H. Chang, J.-M. Li, and Y.-F. Li, Journal of The Electrochemical Society, 156, A667 (2009)

24. E. Potiron, A. Le Gal La Salle, A. Verbaere, Y. Piffard, and D. Guyomard, Elec trochimica Acta, 45, 197 (1999)

25. J.-M. Li, K.-H. Chang, and C.-C. Hu, Electrochimica Acta, 55, 8600 (2010)

26. D. Vernardou, A. Sapountzis, E. Spanakis, G. Kenanakis, E. Koudoumas, and N. Katsarakis, Journal of The Electrochemical Society, 160, D6 (2013).

27. K. Takahashi, S. J. Limmer, Y. Wang, and G. Cao, Journal of Physical Chemistry B, 108, 9795 (2004).

28. N. Nagarajan, H. Humadi, and I. Zhitomirksy, Electrochimica Acta, 51, 3039 (2006)

29. J. Livage, Solid State Ionics, 86-88, 935 (1996).

30. F. Bellenger, C. Chemarin, D. Deroo, S. Maximovitch, A. Surca Vuk, and B. Orel, Electrochimica Acta, 46, 2263 (2001).

31. M. Pourbaix, in Atlas d'Équilibres Électrochimiques, p. 168 (1963).

32. K.-H. Chang and C.-C. Hu, Acta Materialia, 55, 6192 (2007).

33. C. Zuo and P. W. Jagodzinski, The journal of physical chemistry. B, 109, 1788 (2005)

34. N. Guillot and M. Lamy de la Chapelle, Journal of Quantitative Spectroscopy \& Radiative Transfer, 113, 2321 (2012).

35. C. Julien, M. Massot, S. Rangan, M. Lemal, and D. Gyuomard, Journal of Raman Spectroscopy, 33, 223 (2002).

36. J. Luo, H. T. Zhu, H. M. Fan, J. K. Liang, H. L. Shi, G. H. Rao, J. B. Li, Z. M. Du, and Z. X. Shen, The Journal of Physical Chemistry C Letters, 112, 12594 (2008).

37. M. S. Whittingham, Journal of the Electrochemical Society, 122, 713 (1975). 